\title{
APOIO AO DOCENTE EM INÍCIO DE CARREIRA: IMPACTOS NA INDUÇÃO PROFISSIONAL DE PROFESSORES DO PROGRAMA RESIDÊNCIA DOCENTE DO COLÉGIO PEDRO II
}

\author{
AMANDA OLIVEIRA RABELO ${ }^{1}$ \\ ORCID: https://orcid.org/0000-0001-6488-3138 \\ ANA MARIA MONTEIRO ${ }^{2}$ \\ ORCID: https://orcid.org/0000-0002-8114-3198
}

\begin{abstract}
RESUMO: O objetivo da presente pesquisa é analisar a ação de indução profissional em docentes recémformados, com foco no diálogo entre instituição de formação e escola, relacionando a ação com os seus resultados. Abordagens quantitativas, qualitativas e narrativas foram usadas para investigar docentes dos anos iniciais do ensino fundamental e da educação infantil que participam de um programa que auxilia a indução profissional de professores recém formados, a saber: o programa piloto Residência Docente do Colégio Pedro II, na cidade do Rio de Janeiro/Brasil. Analisamos o impacto desse Programa na indução profissional por meio da aplicação de questionários e entrevistas focados: Investigou-se particularmente as dificuldades encontradas durante a prática pedagógica; o papel dos professores orientadores regentes (da escola básica, do Colégio Pedro II) e dos supervisores docentes do Programa e a influência deste no início da atuação profissional e nos locais onde trabalham. Por fim, esta investigação visa dar visibilidade a políticas de apoio a professores iniciantes para que possam se desenvolver profissionalmente e, até mesmo, diminuir sua desmotivação e o eventual abandono da docência, bem como contribuir para ampliar as poucas experiências existentes nessa área, no Brasil.
\end{abstract}

Palavras-chave: indução profissional docente, professores iniciantes, formação de professores, profissão de docente, residência docente.

\section{SUPPORT FOR EARLY CAREER TEACHERS: IMPACTS ON THE PROFESSIONAL INDUCTION OF TEACHERS IN THE TEACHER RESIDENCY PROGRAM OF PEDRO II SCHOOL}

\begin{abstract}
The purpose of this research is to analyze the action of professional induction in recently graduated teachers, focusing on the dialogue between training institution and school, relating the action with its outcomes. Quantitative, qualitative and narrative approaches were used to investigate teachers of the early years of elementary school and early childhood education who participate in a program that helps the professional induction of newly graduated teachers, namely: the pilot program Residency Teacher of Pedro II School, in the city of Rio de Janeiro/Brazil. We analyzed the impact of this Program

\footnotetext{
${ }^{1}$ Professora Associada da Universidade Federal Rural do Rio de Janeiro, UFRRJ. Seropédica, RJ, Brasil. Jovem Cientista da FAPERJ.<amandaorabelo@hotmail.com>

2 Professora Titular da Universidade Federal do Rio de Janeiro, UFRJ. Rio de Janeiro, RJ, Brasil. Pesquisadora CNPQ.
} $<$ anammonteiro22@gmail.com>
\end{abstract}


on professional induction through the application of focused questionnaires and interviews: We investigated particularly the difficulties encountered during the pedagogical practice; the role of the regular supervising teachers (from the basic school, the Pedro II College) and the teaching supervisors of the Program and its influence on the beginning of the professional practice and in the places where they work. Finally, this research aims to give visibility to policies of support for beginning teachers so that they can develop professionally and even reduce their demotivation and eventual abandonment of teaching, as well as contribute to expand the few existing experiences in this area in Brazil.

Keywords: professional teaching induction, beginning teachers, teacher training, teaching profession, teaching residency.

\section{APOYO AL PROFESORADO EN EL INICIO DE CARRERA: IMPACTOS EN LA INDUCCIÓN PROFESIONAL DEL PROGRAMA RESIDENCIA DOCENTE DEL COLEGIO PEDRO II}

RESUMEN: Esta investigación tuvo como objetivo realizar un estudio sobre una acción de inducción profesional por parte del docente recién egresado, con foco en el diálogo entre la institución formadora y la escuela, relacionando la acción con sus resultados. Utilizando enfoques cuantitativos, cualitativos y narrativos como metodología, realizamos una investigación con docentes de los primeros años de la escuela primaria y educación infantil, participantes de un programa que asiste a los docentes recién formados en su inducción profesional, el Programa Piloto de Residencia Docente del Colégio Pedro II en Río de Janeiro / Brasil. Nuestro objetivo fue analizar el impacto de este Programa en la inducción profesional de estos docentes, a través de cuestionarios y entrevistas, enfocándonos en las dificultades que encuentran en su práctica pedagógica, la importancia de la asistencia que les brindó el Programa, el rol de los docentes orientadores (del colegio) del Colegio Pedro II, de los responsables docentes del Programa, al inicio de sus actividades profesionales y en su relación con su colegio. Finalmente, esta investigación ofrece contribuciones para apoyar acciones de docentes principiantes para un mejor desempeño profesional e incluso como una forma de reducir la desmotivación y abandono docente, así como para la expansión de las pocas experiencias existentes en esta área en Brasil.

Palabras clave: inducción profesional docente, docentes principiantes, formación docente, profesión docente, residencia docente. 


\section{INTRODUÇÃO}

Ao reafirmar a temática do dossiê "Formação docente e prática pedagógica - tempos, tensões e invenções", defendemos que professores aprendem a ensinar com o tempo, ao construirem a si próprios como profissionais, especialmente a partir das experiências adquiridas tanto de vida como em seu processo complexo e contínuo de formação e trabalho. Nesse sentido, destacamos aqui o início da carreira docente, ou da indução profissional docente. Esse período tem sido abordado por diversos autores (por exemplo HUBERMAN, 2000; SILVA, 1997) como uma fase crucial da aprendizagem desses profissionais ao possibilitar sua permanência na profissão ou, ainda, à sua desistência, diante do "choque de realidade" com o qual têm que lidar.

Em geral, professores em início de carreira se vêem sós em sua prática profissional e em sua permanência nela. Em grande medida, professores iniciantes só experienciaram a prática profissional durante curtos estágios obrigatórios que não os preparam para o início da docência, o que gera dificuldades. A situação torna-se ainda mais desafiadora quando são encaminhados para as turmas consideradas mais "complicadas" e "problemáticas" das escolas, visto que as instituições costumeiramente fazem uso da "regra" "autoridade é posto", ou seja, professores que estão há mais tempo na profissão escolhem primeiro suas turmas. (ver RABELO e MONTEIRO, 2019).

Nesse sentido, existe uma tendência internacional de implementação de programas que auxiliem docentes em início de carreira, denominada "indução profissional". Entretanto, isso ainda não acontece no Brasil. Vários estudos comprovam que poucas ações inovadoras de apoio ao professor iniciante têm sido implementadas (ver RABELO E MONTEIRO, 2019; ANDRÉ, 2012). Contudo, apresentam bons resultados e servem de modelo para outras iniciativas.

Assim, o objetivo da pesquisa ${ }^{3}$ realizada em 2018, com apoio do CNPQ, foi estudar ações de indução profissional do docente recém-formado, com foco no diálogo entre instituição de formação e escola, ao analisar as ações e os resultados dessas ações. Acompanhamos docentes dos anos iniciais do ensino fundamental e da educação infantil que participaram de um programa para auxiliar os recém formados em sua indução profissional entre 2012 e 2018: o programa piloto Residência Docente do Colégio Pedro II, na cidade do Rio de Janeiro/Brasil. Essa iniciativa teve como objetivo analisar o impacto do programa na indução e inserção profissional desses docentes.

Inquirimos, por meio de questionário, professores em início de carreira que fizeram parte do Programa Residência Docente (PRD) do Colégio Pedro II de auxílio a professores iniciantes, acerca das dificuldades encontradas na prática pedagógica e sobre o auxílio dado pelo programa para sua indução profissional. Em um segundo momento, entrevistamos alguns dos professores sobre as dificuldades da prática pedagógica, sobre a ajuda prestada pelo programa à sua indução profissional, e sobre o papel dos professores orientadores regentes (da escola básica do Colégio Pedro II - CPII) - assim como dos supervisores docentes, no início de sua prática profissional e em relação à escola onde trabalham. Por fim, compartilhamos os resultados dessa investigação e incentivamos a revalorização dos programas existentes, assim como a ampliação do número de ações, de beneficios e financiamentos, nessa área no Brasil.

\section{METODOLOGIA}

Os estudos quantitativos e qualitativos, narrativos e comparativos propostos por Sampieri, Collado e Lucio (2006) em seu modelo multimodal e misto de investigação - o qual converge tais enfoques -, foi a metodologia adotada em nosso estudo. A amostra foi composta por docentes dos anos iniciais do ensino fundamental e da educação infantil que participam do programa piloto Residência Docente do Colégio Pedro II, na cidade do Rio de Janeiro/Brasil, o qual acompanha docentes recémformados em sua indução profissional, por meio de ações inovadoras.

\footnotetext{
${ }^{3} \mathrm{O}$ apoio ao docente em início de carreira: impactos na inserção profissional docente do programa residência docente do Colégio Pedro II e de outros programas nacionais e internacionais. 
Utilizamos o método geral de investigação narrativa explicado por Ponte et al (1998, p. 31), que consiste em compreender e reconstruir unidades narrativas a partir de entrevistas ao priorizar o processo "categórico-conteúdo". Entretanto, não deixamos de lado o processo "holístico-conteúdo", que tem como foco os conteúdos apresentados pelo indivíduo (LIEBLICH, TUVAL-MASHIACH, ZILBER, 1998). Nesse sentido, adotamos o quadro global da metodologia de investigação narrativa, centrado no método interpretativo, o que foi aplicado às narrativas obtidas durante as entrevistas. Também analisamos as narrativas/discursos escritos nos questionários. Os dados estatísticos fornecidos durante o processo de coleta de informações possibilitaram construir análises, compreendendo em profundidade os aspectos abordados no questionário e na entrevista. Os dados coletados também possibilitaram a análise do conjunto de professores investigados, ao considerar que cada vida é única, embora o indivíduo tenda a buscar padrões comuns - ou seja, indivíduos constroem descrições, medidas e observações que influenciam, e são influenciados, pelo outro (BOLÍVAR et al, 2001).

\section{Estratégias e Instrumentos elaborados e utilizados}

Elaboramos e aplicamos um questionário composto por questões objetivas e subjetivas em docentes que finalizaram a participação no Programa e um questionário menor desenvolvido para docentes que haviam somente iniciado sua participação no programa. Por fim, realizamos entrevistas narrativas acerca do impacto desse programa na inserção e prática profissional de docentes que finalizaram sua participação nele e que já estavam exercendo sua prática de ensino.

Todos os docentes dos anos iniciais do ensino fundamental e da educação infantil participantes do programa entre 2012 e 2018 formaram o universo de aplicação do questionário - no total, 101 questinários foram enviados. Porém, somente 57 foram efetivamente respondidos e devolvidos para análise. Também realizamos 10 entrevistas, das quais: 5 entrevistas iniciais com coordenadores (dois coordenadores foram entrevistados, em conjunto) e 5 entrevistas com formandos do curso (os quais foram selecionados após a aplicação do questionário). Dessas, 9 entrevistas foram transcritas.

O questionário foi elaborado de acordo com discussões efetuadas por Marcelo (1999), Nóvoa (2017) e André (2012), após extensiva revisão bibliográfica sobre o tema, abrangendo 7 eixos de questões/análise, a saber: 1- dados pessoais; 2- motivação para escolha do programa; 3- problemas do cotidiano escolar antes da entrada no programa; 4- experiência no programa; 5- dificuldades vividas durante o programa; 6- auxílio do programa para a solução de dificuldades; 7- contribuição das atividades do programa para a prática docente.

O primeiro eixo do questionário continha questões sobre dados pessoais, incluindo escolaridade, tipo de formação, tempo de formação e serviço, quando iniciou no programa, quando (e se) concluiu o programa, bem como expectativas pós-programa. O segundo eixo abordava as motivações para a escolha do programa. As respostas seguiram o tipo escala Likert (1-5), segundo a qual 1 representou "nada importante" e 5 significou "muito importante". As motivações elencadas foram divididas em: obtenção de diploma, apoio nas dificuldades, conhecimento, bolsa de estudo e outras. Enumeramos tais motivações a partir de entrevistas iniciais com as/os coordenadores do programa. O terceiro eixo, "problemas do cotidiano escolar antes da entrada no programa", apresentou frases com respostas baseadas na escala Likert que descreviam diversos problemas observados no cotidiano escolar. As frases foram elaboradas a partir dos quatro tipos básicos de conflitos e tensões vividos por professores iniciantes definidos por Beach e Pearson (1998, p. 339-340): conflitos de currículo e instrução; conflitos de relacionamento interpessoal; conflitos de autoconceito ou papel; conflitos contextuais e institucionais.

Com base nas dimensões descritas acima, elaboramos frases substanciadas pelos dizeres de alunos estagiários da formação inicial docente e de professores encarregados de monitorar tais estagiários. Eram frases que ouvíamos quando ainda eramos docentes da disciplina "Prática Pedagógica". Algumas delas também resultaram de questões analisadas na pesquisa "Prática pedagógica no ensino público: o estágio como elo entre a teoria e a prática, a experiência e a inovação", a qual foi financiada pelo CNPQ. A escolha desse caminho justifica-se pelo fato de que, praticamente todas as pesquisas sobre professores em início de carreira, como por exemplo: Huberman (2000); Alarcão e Roldão (2014); Nóvoa (2017); Papi e Martins (2008); Corrêa e Portella (2012); Marcelo (1999); Flores e Ferreira (2009); Cardoso e 
Ferreira (2008); Cochran-Smith et al (2012), apontam suas muitas dificuldades. Essas descobertas trazem à tona a necessidade de apoiar os professores nessa fase de suas carreiras.

O quarto eixo, "experiência no Programa", abordou frases respondidas pela escala Likert acerca da aquisição de experiência durante o programa, sobre o que o docente buscava nele, e sobre o conhecimento adquirido (ou não). Esse eixo teve como objetivo relacionar as dificuldades citadas no eixo anterior a respeito das experiências que tiveram durante o programa - tais frases também foram baseadas na entrevista realizada com os coordenadores de curso.

O quinto eixo, "dificuldades no programa", apresentou frases com respostas na escala Likert que justificavam algumas dificuldades que poderiam ter surgido no decorrer do programa, fossem elas pessoais ou profissionais. Tais dificuldades foram descritas pela coordenadora do programa, entre 2012 e 2016 (ver Costa, 2017), e também foram mencionadas em entrevistas com as coordenadoras de área do programa. O sexto eixo, "auxílio do programa nas dificuldades", trouxe à tona aspectos do cotidiano escolar; os respondentes deveriam marcar o nível de importância do programa Residência Docente para o auxílio na melhoria dos aspectos abordados. Suas respostas corresponderam à escala likert (1 a 5), na qual 1 significou "O programa não ajudou nada" e 5, "o programa ajudou muito". Relacionamos os problemas descritos no nosso segundo eixo com a possibilidade de o programa ter auxiliado na superação de dificuldades profissionais. Adaptamos alguns itens descritos no questionário avaliativo do próprio programa (questionário avaliatiavo PRD-2016). O sétimo eixo, "contribuição das atividades do programa com a prática docente", apresentou todas as atividades descritas no site do programa e solicitou aos respondentes que baseassem as frases na escala Likert (1 a 5), na qual 1 significou "não contribuiu nada" e 5 , "contribuiu muito".

Selecionamos 5 docentes entre aqueles que responderam o questionário para a entrevista. A escolha foi baseada em respostas que precisavam ser aprofundadas; 3 selecionados participaram do programa até o final, e 2 haviam desistido do curso. As entrevistas seguiram o roteiro elaborado de acordo com categorias afins às do questionário. Porém, a análise que efetuamos seguiu uma categorização posterior, a qual teve como base as narrativas contidas nas entrevistas, assim como a análise efetuada das respostas subjetivas do questionário.

As narrativas contidas nas entrevistas e nas questões abertas dos questionários possibilitaram selecionar as informações sobre as vivências dos docentes, analisar os significados presentes nelas e sua relação com a sociedade, assim como suas instituições e seus enunciados - fator fundamental em estudos comparados. Os inquéritos visavam validar, complementar e confirmar a análise das narrativas dos entrevistados.

Utilizamos essas duas técnicas (entrevistas e inquéritos via questionário) para articular dados e completar as informações (Martins, 1996). Ao fazer tal conjugação, ambicionamos abranger o potencial de cada uma dessas técnicas, principalmente a extensividade dos questionários, que permitiu comparações e extrapolações, e a profundidade das entrevistas, que nos ajudou a melhor apreender certas questões e a captar informações mais subjetivas - assim como a minimizar suas limitações. Entrevistas restritas a poucos indivíduos são exemplo de tais limitações, vito que esse processo reduziu a possibilidade de generalizações. Outro examplo é a superficialidade dos inquéritos via questionários, pois eles não nos permitiram compreender as vivências subjetivas).

Consideramos as interpretações decorrentes do processo de pesquisa como específicas do, e pertencentes ao universo investigado. Dessa forma, não pretendemos que se tornem universais, ainda que todo estudo contribua para o desvendamento de questões pertinentes a um determinado campo de conhecimento. Em outras palavras, embora específicos e contextuais, permitem-nos que alcemos voos teóricos, para além das análises efetuadas.

\section{O PROGRAMA RESIDÊNCIA DOCENTE DO COLÉGIO PEDRO II}

O Colégio Pedro II (CPII), criado em 1837, foi o primeiro de Instrução Secundária oficial do Brasil. Desenvolvido para ser modelo de instrução secundária, ainda mantém hoje sua tradição e é considerado uma instituição de educação pública referência no Brasil. O colégio busca a vanguarda de 
seu ensino e a excelência de seu corpo docente, a qual é alcançada por meio de seleção rigorosa e concorrida. O Programa de Residência Docente (PRD) foi criado em maio de 2012 no CPII, o primeiro programa de pós-graduação da instituição, a pedido da CAPES, a qual o fomentou entre 2012 e 2015. O programa:

visa aprimorar a formação do professor da Educação Básica por meio de um projeto de formação continuada, desenvolvendo competências docentes que complementem a formação recebida na Instituição de Ensino Superior (IES) de origem, a partir da vivência em um ambiente escolar de reconhecida excelência.

A Residência Docente pareia professores recém-formados (aqui denominados Residentes Docentes) com professores orientadores do Colégio Pedro II (Professores Supervisores e Coordenadores de Área), de modo a dar ao novo profissional uma formação complementar em questões de ensino-aprendizagem na área/disciplina, assim como em aspectos da vida escolar. Além disso, pretende possibilitar a aplicação de novas metodologias e estratégias pedagógicas na instituição de atuação do Professor Residente, que venham a incrementar os resultados de aprendizagem dos alunos da Educação Básica. (Site do CPII, grifos nossos).

O público-alvo do programa é formado por professores da rede pública estadual e municipal os quais estão em regência de turma, com diploma em Licenciatura Plena e atuantes nas áreas/disciplinas da Educação Básica oferecidas pelo programa. Após a conclusão do curso, os residentes são certificados pelo CPII como Especialistas em Educação Básica (pós-graduação Lato Sensu).

Entretanto, constituído, em grande medida, por residentes que são professores em início de carreira, a seleção dos residentes não se restringe a professores recém-formados. Uma das fases de classificação utiliza critérios de idade( professores mais jovens seguidos pelos mais velhos) e de tempo de conclusão do curso; logo, alguns docentes que participaram do curso não eram recém-formados.

Desde 2016, residentes têm que cumprir a carga horária de 360 horas, as quais são distribuídas por um período de um ano letivo, entre atividades presenciais e à distância, bem como entre atividades desenvolvidas na escola em que atuam, a saber: atividades na área de docência - atividades didáticas desenvolvidas no CPII e na unidade escolar do residente; atividades em setores administrativopedagógicos do CPII; atividades voltadas para a formação continuada - oficinas, congressos etc.. Os residentes devem, ainda, entregar algumas tarefas escritas, como relatórios, um memorial circunstanciado e um produto final que associe o que ele vivenciou no CPII ao que ele vive na sua realidade de regente em outras classes.

Além dos residentes, outros profissionais envolvidos no Programa são: Professor Supervisor (professores efetivos do CPII nas diversas áreas que recebem e supervisionam residentes em suas salas de aula); os Coordenadores de Área (professores pós-graduados do CPII que, além de coordenar a área do Programa, também acompanham e controlam as atividades de cada residente em sua escola de origem); Coordenação do Programa.

Os residentes precisam cumprir a carga horária didática de observação e participação, como se fosse um estágio curricular, no CPII, na sala de aula do Professor Supervisor. Em outras palavras, seu mentor não é um professor da escola onde trabalha, nem faz supervisão presencial na escola de origem do residente. Esse processo tem como objetivo fornecer informação acerca das inovações realizadas no CPII ao prover vivências para residentes em um ambiente escolar de reconhecida excelência.

Porém, normalmente, como osprofessores de anos iniciais do EF e da educação infantil áreas aqui investigadas - cumpriam carga horária de trabalho em tempo integral, muitos residentes tinham dificuldade em cumpri-la.. Tal impasse de agenda gerava um dos principais problemas apontados pelos coordenadores: a evasão de docentes. Entre 2013 e 2016, a evasão de docentes dos anos iniciais do ensino fundamental e da educação infantil chegou a $28,16 \%$. Na maior parte das vezes, essa evasão era ocasionada por problemas de conciliação de horários entre Professores Supervisores e Residentes Docentes que também trabalham, e não tinham dispensa de suas atividades, para cumprirem sua carga horária no CPII.

\section{RESULTADOS}


Os resultados apresentados nos 57 questionários devolvidos foram correlacionados com informações que obtivemos na categorização das entrevistas realizadas: 10 entrevistas, 5 com formandos do curso, e 5 com coordenadores (dois coordenadores foram entrevistados conjuntamente. No total, - 9 entrevistas foram transcritas).

Os resultados serão apresentados com base nos 7 eixos de questões/análise do questionário: 1- dados pessoais; 2- motivação para a escolha do programa; 3- problemas do cotidiano escolar vividos antes da entrada no programa; 4- experiência adquirida durante o programa; 5- dificuldades vivenciadas durante o programa; 6- auxílio do programa para solução de dificuldades; 7-contribuições das atividades do programa para a prática docente. As entrevistas foram inseridas dentro desses eixos da análise aqui descrita, embora as entrevistas tenham sido categorizadas a posteriori. Assim, elas foram além dos eixos mencionados e possibilitaram análises diferentes acerca das presentes nos questionários.

Cabe informar aqui que obtivemos do questionário um alfa de Cronbach de 0,905. Assim, podemos inferir que o questionário aplicado tem coerência; não é redundante, nem cheio de perguntas desconexas - fato que avalisa a qualidade do instrumento e a confiabilidade das conclusões da pesquisa.

\section{Dados Pessoais e Formação Profissional}

O primeiro eixo do questionário contém questões sobre dados pessoais, incluindo escolaridade, tipo de formação, tempo de formação e de serviço, bem como início no programa, se concluiu (ou não) o programa e expectativas pós-programa.

A maior parte dos docentes eram jovens entre 21 e 30 anos (43,9\%), a qual foi seguida por participantes entre 31 e 40 anos (42,1\%), e por aqueles com mais de 41 anos (14\%). A maior parte dos docentes lecionava nos anos iniciais do ensino fundamental (70,2\%); 29,8\% lecionava na educação infantil; além de ter cursado o programa específico para os anos iniciais (71,9\% e 28,1 respectivamente).

Com relação ao tempo de conclusão da licenciatura ao início do curso, percebemos que a maior parte dos participantes se formou entre 1 a 3 anos (38,6\%); 12,3\% dos participantes tinha até um ano de licenciatura. Assim, podemos concluir que o total de 40,9\% de docentes era recém formada.

Ainda não há consenso nas pesquisas acadêmicas sobre o real período da indução profissional, ou do início de carreira docente. Huberman (2000) indica que tal fase iria até o terceiro ano da carreira. Outros autores, como Silva (1997), destacam o primeiro ano da carreira como o mais complicado e o que necessita de maior apoio. Assim, alguns programas de indução profissional internacionais concentram-se no primeiro ano de atuação profissional do docente; outros programas abrangem tempos de assistência mais longos (ver RABELO, 2019). Portanto, dados sobre idade e tempo de conclusão do seu curso da maior parte dos docentes em nosso estudo se mostram pertinentes à pesquisa em tela.

No que se refere ao caso particular do Colégio Pedro II, notamos que o programa prioriza professores em início de carreira, mas não se limita a eles. Percebemos que 10,5\% dos profissionais que responderam ao questionário tinham até 1 ano de docência e 35,1\% tinham de 1 a 3 anos de docênica. Logo, $45,6 \%$ dos docentes estariam realmente nessa fase inicial na carreira. Embora tenhamos encontrado também 38,6\% de participatntes que tinham entre 3 e 6 anos de docência; 8,8\% deles tinha de 6 a 10 anos de docência e 7\%, com mais de 10 anos de docência.

A maior parte dos docentes pertenciam à rede municipal de ensino da prefeitura do Rio de Janeiro (54,4\%), e eram seguidos por professores de outros municípios do Estado do Rio de Janeiro $(40,4 \%)$ e por outras opções $(5,3 \%)$.

A maioria dos respondentes que concluiu o programa não recebeu bolsa $(54,4 \%)$ para a realização do curso. No total, 42,11\% dos particopantes concluiu o curso; 14,03\%, estava terminando; $35,09 \%$, estava iniciando o programa; e 8,77\%, desistiu dele.

Os docentes analisados almejavam aprofundar seus conhecimentos e continuar seus estudos. Por isso, perguntamos nas entrevistas quais seriam suas aspirações profissionais. Os respondentes narraram o desejo de realizar mestrado ( $50 \%$ ), ou outra pós-graduação $(25 \%)$, bem como de serem aprovados em processos de seleção para trabalharem no Colégio Pedro II (25\%). 
Para escolher os profissionais docentes que participariam das entrevistas, com exceção dos coordenadores, perguntamos sobre a história de vida dos entrevistados. Verificamos grandes diferenças com relação à escolha profissional entre eles. Somente dois entrevistados alegam ter escolhido a docência porque sempre desejaram ser professores. Os outros demonstraram diferentes motivações, inclusive a inspiração de um professor que tiveram no passado (1 entrevistado), a motivação do estágio (1 entrevistado), escolha por falta de outra opção (1 entrevistado) ou por imposição da mãe (1 entrevistado).

\section{Motivação para escolher o programa}

O segundo eixo de análise do questionário tem como foco as motivações para a escolha do programa. De acordo com os resultados registrados para as questões desse eixo, podemos perceber que a maior parte das respostas indicam como motivação para a escolha do curso: a obtenção de conhecimento, apoio para superar dificuldades e obtenção de um diploma. Os inqueridos eram praticamente indiferentes com relação à bolsa de estudos. Alguns docentes especificaram alguns outros motivos para esta escolha, no questionário:

Fiz inscrição com o intuito de conhecer uma instituição tida como de "excelência em ensino". P24

Voltar aos estudos depois de 2 anos parada após a graduação. P44

Conhecer a proposta curricular do Pedro II. P51

Nas entrevistas, quando perguntados sobre sua motivação para a realização do curso, os docentes explicaram que o conhecimento adquirido foi mais importante. Esse fator foi seguido pela obtenção do certificado e pelo fato de ser um curso gratuito. Eles também citaram a importância de obter um apoio:

\footnotetext{
As pessoas fazem muito por conta do diploma. A maioria das pessoas que estavam fazendo residência docente não era para acrescentar [...], as pessoas queriam um diploma de pós, ou para enquadrar, ou para outra coisa. (P.E.)

Passou uns anos... um tempo sem estudar... e foi me dando vontade de fazer alguma coisa, [...] eu vi uma colega minha no grupo de professores postando essa [...] especialização específica para professores da rede pública, eu me enquadrei nesse perfil, era de graça também [...] fui lá e me inscrevi na intenção de saber como é que é, não foi nem na intenção de ter uma especialização. A especialização, em termos de dinheiro, na prefeitura do Rio, não vale nada. (P.P.)

Quando eu entrei [na carreira pública] eu comecei a pensar: "bom, eu preciso de mais formação, só o que eu tenho não é suficiente, preciso buscar mais" e comecei a buscar [...] pensei em um mestrado, [...] mas nas instituições públicas até hoje nenhuma delas oferece um mestrado que atenda o professor que trabalhe com Fundamental I [...] porque todas elas trabalham com a ideia do professor que consegue ter um dia livre na semana e não é nossa realidade[...], a gente não tem um mestrado que seja oferecido a noite, que seja oferecido aos sábados, então não é para a gente. Então, [...] comecei a procurar e encontrei o PRD que oferecia um horário muito flexível, um horário que eu conseguia adequar à minha rotina de trabalho. Então foi por isso que, quando eu vi uma pós que se propunha dialogar com a minha sala de aula, que era diferente, pelo menos quando eu li a proposta, era uma pós graduação que partiria do meu trabalho em sala, que estaria atrelada a isso, era uma proposta que não tinha encontrado nas outras e juntou a questão do horário, "ah, então é essa" e me inscrevi. (P.A.)
}

A bolsa de estudos foi citada como importante somente pelos coordenadores. Os docentes disseram que ao optarem pelo curso, nem se atentaram para a questão de ele oferecer uma bolsa de estudo, mesmo que ela fosse boa. Para alguns respondentes, o fato de fazerem uma pós-graduação gratuita, por si só, já justificava a escolha pelo curso.

Os entrevistados afirmaram que o curso não tinha ampla divulgação; portanto, perguntamos a eles como tomaram conhecimento. 2 disseram que foi por indicação; 2, por pesquisa na internet e 1, por acaso. 
O terceiro eixo, "problemas do cotidiano escolar antes da entrada no Programa", apresenta descrições de diversos problemas enfrentados no cotidiano escolar. As frases que obtiveram maior concordância por parte dos inquiridos foram: o professor precisa de um apoio no início de sua carreira profissional; precisa trocar conhecimentos; e que precisa dar conta de todos os aspectos sociais na escola. As frases com as quais os professores mais discordaram relacionavam-se ao fato de o estágio ser curto e de que pais de alunos não entendiam a forma de ensinar do professor. As outras não tiveram nem muita concordância nem muita discordância.

Dados os tipos básicos de conflitos e tensões vividos pelos professores iniciantes definidos por Beach e Pearson (1998), podemos destacar aqueles que tiveram maior concordância por parte dos docentes: aqueles relacionados aos conflitos "contextuais e institucionais", incluindo expectativas com o preparo dado pela Universidade sobre o sistema escolar; conflitos de "currículo e instrução" com relação às dúvidsa sobre como lidar com o ensino dos conteúdos escolares - menor valor foi dado a conflitos de "autoconceito ou papel" e de relacionamento "interpessoal".

Com respetito à questão aberta, no questionário sobre o início da carreira de docente, alguns professores expressaram suas opiniões acerca das dificuldades encontradas antes de seu ingresso no programa e sobre a contribuição do curso para a solução deles. Essas respostas mostraram que o Programa Residência Docente foi muito importante para esses profissionais, dados os vários relatos que exaltaram sua relevância, em especial para a prática pedagógica cotidiana. Outros descreveram que não tiveram dificuldade no seu início de carreira, porém que procuravam estudar e construir sua prática profissional.

Tendo como base a teoria educacional (HUBERMAN, 2000; ALARCÃO \& ROLDÃO, 2014; PAPI \& MARTINS, 2008; CORRÊA \& PORTELLA, 2012; MARCELO, 1999; FLORES \& FERREIRA, 2009; CARDOSO \& FERREIRA, 2008; AUTORAS, 2019), podemos concluir que professores em início de carreira vivenciam muitas dificuldades, e que precisam de apoio nesta fase da carreira. Entretanto, na maior parte das vezes, não recebem ajuda nas escolas nas quais trabalham ou mesmo na Universidade. Esse dado foi confirmado pelas respostas nos questionários.

As entrevistas mostraram várias narrativas acerca dos aspectos citados nas frases sobre apoio e dificuldades no início da carreira, bem como a estratégia de mudar de escola para tentar resolver os problemas da docência. O maior apoio vinha aparentemente da gestão (escolar, ou da prefeitura), dos pais de alunos, dos colegas e da troca de conhecimentos. Contudo, as dificuldades frente aos mesmos atores: gestão, colegas, pais de alunos, também foi recorrente, além da falta de formação, falta de estrutura e materiais, violência na escola, os próprios alunos, desânimo e auto-questionamento; as dificuldades foram mais citadas do que fatores relacionados ao apoio recebido. Todos os entrevistados citaram as dificuldades listadas acima, e, em contrapartida, somente metade deles citou o recebimento de apoio; 2 entrevistados também citaram que mudaram de escola para resolver suas dificuldades no ensino.

Ainda com relação à compreensão de que o estágio e a graduação lhes prepararam para o início da carreira profissional, a maior parte dos respondentes destacou que não foram bem preparados por eles. Contudo, algumas experiências vividas por eles demonstram que o estágio e a graduação podem ser bons, mas outras experiências mostram que a culpa pela formação deficiente pode estar no próprio indivíduo, quando ele não aproveita sua fase de formação inicial e estágio.

A constatação das dificuldades e da falta de apoio experienciada pelos professores em início de carreira comprova a conclusão de Lima (2004): professores iniciantes estão cada vez mais sozinhos e responsabilizam-se sozinhos por sua permanência na profissão.

\section{Experiências vividas durante o programa}

O quarto eixo, "experiência no Programa", traz afirmativas acerca da experiência do docente durante o Programa, sobre o que o docente buscava nele e o conhecimento adquirido (ou não). Podemos perceber nas respostas dos questionários, a grande importância do curso para a atuação profissional dos 
docentes, principalmente pelo fato de a grande maioria deles ter concordado que o programa os ajudou a superar as dificuldades na docência, assim como com a importância dos supervisores, das trocas de conhecimento, da contribuição do conhecimento adquirido no programa sobre o relacionamento entre teoria e prática. Porém, a maioria não concordou com a afirmação de que o curso não troxe $o$ conhecimento e/ou a habilidade que esperavam.

Tal importância também foi demonstrada nas entrevistas, quando os docentes deram maior destaque aos aspectos positivos do curso, como os exemplos em algumas narrativas, citadas a seguir:

Descobri que não era só especialização na teoria pela teoria, mas que tinha muitas outras discussões sobre a prática e eu achei muito interessante também[...] tanto as oficinas, os minicursos, a gente sempre assistia e participava com pessoas de outros cursos, eu acho que isso acrescenta muito também [...] ver a realidade dos outros professores, tinha professor de Educação Física, professor de língua portuguesa, muito boas essas discussões [...] e até mesmo dentro da minha área poder conviver com diversas realidades porque tinha gente de várias prefeituras, gente de muito longe, então foi bem gratificante. (P.C.)

Todas as questões, os cursos, os minicursos, isso fez eu mudar completamente a maneira de trabalhar, porque eu fui entendendo realmente qual era o trabalho da Educação Infantil, como que nós devemos enxergar a criança, a questão da alfabetização [...] tem essa pressão da alfabetização precoce, [...] foi lá, nos cursos, nas conversas com os professores que têm que preparar essa criança para no ensino fundamental [...] ela, de fato, ser alfabetizada, que é um processo, que demora. $\mathrm{Na}$ Educação Infantil, tem que ter vivência, experiência, [...] eu já tinha feito curso que sempre falou isso, mas na prática na residência docente foi fundamental, porque eu vi que realmente não precisa ficar fazendo cópia, não, tem outras formas de se trabalhar, de formas diferentes do que aquela forma tradicional que ainda muita gente ainda insiste em fazer, então foi fundamental [...] então eu acho que é um curso muito válido, muito importante (P.K.) Meu sonho de trabalho, trabalhar no Pedro II (risos). Assim, realmente, lá você tem todas as possibilidades de fazer, mas eu penso que a gente faz a nossa realidade. [...] Já que não temos, procuro fazer um trabalho de acordo com o que é possível, entende? O que eu consigo fazer pelas crianças [...]. A gente não consegue fazer um trabalho padrão como o do Pedro II. Mas eu penso que não é porque a gente não tem a estrutura que eles têm, que não devemos tentar oferecer uma coisa melhor para nossas crianças, não é. Eu faço na medida que é possível na realidade que nós estamos, entende? Eu sei que não é o melhor, mas também não deixa a desejar, não é o pior. É o que eu falo com as mães, estudo, tudo que eu faço, nas reuniões eu apresento e mostro a justificativa "eu faço dessa forma por isso, por isso e por isso", e quando elas falam: "ah, mas como é que?...", "gente, calma, lá no Pedro II é assim também, as crianças não ficam sentadas copiando folhinha, tem todo um trabalho". Então eu mostro e falo muito da pós ainda, porque ficou marcado, sabe? Na minha vida profissional, no meu aprendizado a pós marcou muito, foi muito importante, apesar de todas as adversidades para acertar, mas foi importante. (P.K.)

É verdade que as condições de trabalho do Pedro II comparadas às da Prefeitura do Rio é surreal, é uma coisa de outro mundo mesmo, parece que a gente chegou nos Estados Unidos da América, a gente vê as realidades dos professores do Pedro II, só que isso também não é assim um inibidor porque dá para tirar proveito de muitas coisas. [...] Acho que dá para aproveitar muito do que eles fazem lá para nossa realidade, [...] não dá para fazer tudo, mas tipo essa linha de trabalho que eu segui, é uma linha que não precisa de ter as condições do Pedro II para eu fazer, porque dá voz à criança, dá vez à criança, de não comprar aquilo que a criança pode produzir. Essa linha de trabalho que eu aproveitei para mim. (P.P.)

As entrevistas destacaram a importância do Colégio Pedro II, por ser um colégio de referência, que adota metodologias modernas, assim como da importância das discussões práticas efetuadas durante o curso e da troca de conhecimento com colegas de curso. Também falaram da relação com os supervisores, os quais não iam conhecer a realidade enfrentada pelos professores (mas que trouxeram contribuições importantes para os docentes); do produto final, que gerou certa dificuldade, mas que terminou por trazer conhecimento importante para a sua atuação; da relação com a escola e com o curso, a qual é, em geral, complicada, principalmente devido à dificuldade em conciliar cargas horárias e à colisão entre posicionamentos pedagógicas discutidos durante o curso e na escola. Contudo, também defenderam a posição de que o curso proporcionava uma reflexão mais abrangente sobre tais posicionamentos peagógicos - esse item também foi alvo de algumas críticas negativas. 


\section{Dificuldades vivenciadas durante o programa}

O quinto eixo, "dificuldades no Programa”, apresenta afirmativas que expressam algumas dificuldades que poderiam ter surgido no decorrer do programa, sejam elas pessoais ou profissionais. De acordo com os resultados, verificamos que as dificuldades encontradas foram imperceptíveis para a maior parte dos respondente: a vasta maioria discordou da maior parte dos itens sobre dificuldades vivenciadas.

Porém, destacamos que a maior parcela dos docentes que abandonaram o curso não responderam ao questionário; possivelmente, porque estavam com seus e-mails e dados desatualizados. Quase todos os itens foram respondidos por uma ou mais pessoas que vivenciaram alguma dificuldade ninguém apontou qualquer difuldade causada por mudança de domicílio. Logo, nesse caso, isso não significa que não houve dificuldades, mas que a maior parte dos respondentes não passou por elas.

A maioria das respostas à questão aberta descreveu a falta de dificuldades durante o curso e sua importância, conforme as respostas abaixo:

O Programa de Residência Docente foi crucial para o meu crescimento profissional e minha educação continuada. As oportunidades de aprender com o outro, trocar informações e experiências foram bastante ricas para a construção dos meus conhecimentos. P4

Foi uma troca de saberes válida e produtiva. P5

Ao assumir o cargo de professora de educação infantil em 2012 eu busquei me atualizar imediatamente. Busquei muito conhecimento através de pesquisas em livros, internet, revistas e com a gestão da minha unidade. Em 2013 iniciei um curso de extensão na UniRio e em 2014 na UFRJ. Sendo assim, não cheguei atuar de forma completamente tradicional, porém, tinha muitas angústias sobre a relação da teoria e prática. Não tinha propriedade da teoria que regia a minha prática. Hoje após o PRD tenho propriedade do conhecimento teórico que direciona a minha prática. P11

Tive sorte. O Programa foi muito importante para mim. Sou muito contente pelo trabalho acadêmico que pude desenvolver, pelas ações docentes que pude e continuo colocando em prática. P28

Comecei a lecionar meses antes ingressar no PRD, estava muito insegura com minhas práticas. Considero que o programa auxiliou bastante minhas práticas, inclusive fui indicada como a professora alfabetizadora destaque pela gestão da escola a CRE na qual trabalho. Muito feliz por ter o trabalho reconhecido! P29

$\mathrm{Na}$ verdade, não tive dificuldades. P6

Tive supervisores excelentes, que sempre tentavam me atender mesmo com meus horários limitados por conta do trabalho. Nos encontrávamos aos fins de semana e, quando em dias de semana, no horário noturno. Assim, houve total apoio para conseguir concluir o curso no tempo previsto. P27

Algumas respostas abertas apontaram a importância do curso, sem deixar de destacar algumas dificuldades vividas, como demonstram as respostas a seguir:

É um excelente Programa. Indico. Existem dificuldades relacionadas a horários dos minicursos, algumas colegas encontraram dificuldades com sua supervisora que não dava atenção suficiente. P24

Durante o PRD, muitas vezes, tive a percepção de que a maioria dos docentes da instituição CPII pouco estavam interessados com nossa realidade, o interesse maior era demonstrar como eles atuavam sem a preocupação de que existe um vão enorme que diferenciava nossos cotidianos. De minha trajetória, só posso destacar um nome dentro do PRD que estava interessado em trocar conosco e não apenas criticar nossa realidade sem se preocupar com formas de discuti-la e modificá-la. Contudo o programa valeu muito como espaço de troca entre os residentes. P30

Contudo, algumas respostas abertas apontaram certas dificuldades experienciadas durante o curso, como mostram as respostas a seguir:

Não pude participar da maioria das oficinas de manhã e a tarde, pois não recebia dispensa do trabalho. P7 
Havia várias oficinas, palestras e cursos que queria fazer, mas infelizmente o horário não era bom para mim. P10

Eu não fiz o PRD. Me inscrevi, mas ao chegar para realizar a matrícula percebi que fiz a inscrição nos horários e no segmento errados. P23

O programa não emite uma declaração de comparecimento ou um documento que possamos entregar na unidade escolar. Sendo assim, ficamos a mercê do bom senso da direção para liberar o servidor para cumprir a carga horária de residência. Tive muita dificuldade com a dispensa pela falta de um documento acarretando desgaste na escola o que me fez pensar em desistir diversas vezes. P11

Os horários dos minicursos eram bem reduzidos, o que dificultava profundidade nas discussões. P24

Como a carga horária do curso é bem longa, e precisamos ir ao CP2 várias vezes para cumprilas (cursos, minicursos, palestras, encontros com supervisores, horas em sala de aula) o custo de passagem e alimentação acaba sendo um pouco alto. A bolsa fez muita falta nesse sentido. P29 Optei por não iniciar o Programa por não conseguir conciliar o curso com o trabalho. P33

Alguns aspectos dessas dificuldades foram relatados durante as entrevistas. Enfatizamos que as mais destacadas foram:

- o fato dos docentes não serem liberados do seu trabalho pela Prefeitura para realizarem a parte prática do curso - 6 entrevistados citaram esta dificuldade:

ao mesmo tempo que a legislação fala que nós professores temos que ter a educação continuada, nós não temos liberação na prefeitura do Rio para fazer esses cursos, então foi muito complicado porque os cursos de extensão, eu fiz ou a noite, ou sábado porque não podia ser no horário de trabalho e a [...] a residência docente foi muito difícil, quase abandonei várias vezes porque eu não tinha liberação para ir para o campo para observar. [...] Porque o Pedro II não dá uma declaração [...] então tem que fazer acordo com a direção... para as crianças não ficarem sem professor[...] então eu falei que ia assumir a falta, só que minhas colegas assumiram a turma para mim, e eu consegui concluir as minhas horas, [...] então a gente também fica a mercê da direção liberar ou não, algumas até conseguiam mais fácil, mas eu não consegui fácil, não. (P. K.)

- o fato de ser um colégio modelo, que não tem a mesma estrutura da escola na qual trabalham - 4 entrevistados citaram:

Eles não queriam dialogar comigo, queriam falar da realidade deles, das pesquisas deles, do que eles desenvolviam, do que eles achavam que eu deveria desenvolver, eles não estavam interessados em dialogar e conhecer a minha realidade e, às vezes, o que a gente falava da nossa realidade, ficava nítido que, para eles, era uma coisa tão absurda, tão fora do real... quando a gente, a prefeitura do Rio é a maior rede, o real somos nós e eles não viam isso (P.A.)

- o fato de o curso ser igual a um estágio - 4 entrevistados citaram:

Eu queria dedicar meu tempo fazendo uma coisa que me acrescentasse mesmo, que eu pudesse estudar, vislumbrei até um possível mestrado na vida, eu queria estudar e eu fiquei decepcionada porque cheguei lá e era um estágio, exatamente igual ao estágio que fiz no normal, sem tirar nem pôr. (P.E.)

- o fato de faltar um diálogo mais abrangente - 1 entrevistado:

Eu fui um pouco iludida pensando que o curso partiria desse diálogo. Existiam palestras, minicursos... mas muito pouco [diálogo] [...] Era, simplesmente, mostrar o que era feito ou lá ou em outra instituição, que não fosse o Pedro II, fosse outra, mas não querendo dialogar com meu espaço. (P.A.)

- o fato da longa distância a ser percorrida entre o local trabalho e o do curso - 1 entrevistado:

Do Morro dos Macacos tinha que ir para Realengo, [...] de São Cristóvão ia para Realengo, de Realengo tinha que voltar para Tijuca, então tinha a questão do trajeto também. (C.C.) 
- o fato do pouco conhecimento teórico oferecido pelo curso - 1 entrevistado:

Eu imaginei completamente diferente, tudo bem que o nome é residência docente, mas eu achei que ia ser associada a uma teoria, que a gente teria um encontro com um professor, Que fosse "hoje a gente vai para uma aula teórica", alguma coisa que ia preparar a gente até para um fundamento maior, que seguisse carreira na vida acadêmica, [...] mas eu queria associar a teoria à prática (P.E.).

\section{Auxílio do programa para a superação das dificuldades vivenciadas}

O sexto eixo, "auxílio do Programa nas dificuldades" aborda aspectos do cotidiano escolar. Aqui, os respondentes marcam o nível de importância do Programa Residência Docente no tocante ao auxílio para melhorar tais aspectos.

Baseados na análise das médias registradas para todos os itens, podemos perceber os altos índices de auxílio oferecidos pelo programa para a superação das dificuldades vivenciadas no cotidiano da prática docente. Tal formação foi confirmada por duas respostas abertas:

A escola que leciono é muito antiga, e ainda hoje continua em mal estado; não temos pátios para aulas de Educação Física. Os alunos geralmente vão estudar de chinelo de dedo e roupas que dormiram no dia anterior. As frequências das crianças nas séries iniciais são baixas. Tive algumas dificuldades em pôr em prática o que estava aprendendo no Curso, porém ao final do curso o meu trabalho com as crianças (Produto Final) foi recompensador. P10

O Programa abriu um leque de possibilidades que me ajudam a refletir a minha prática e me impulsiona a melhorá-la cotidianamente. Acredito que me tornei uma professora pesquisadora da minha prática. P11

As entrevistas também demonstraram fortemente a realidade descrita acima, pois todos os entrevistados narraram melhorias alcançadas em seu trabalho a partir do que aprenderam e vivenciaram no Programa Residência Docente. As únicas entrevistas que não trataram deste tema foram aquelas realizadas com os coordenadores.

Vários depoimentos apresentaram riqueza de detalhes sobre as formas como isso aconteceu, sobre a mudança na maneira de olhar para o aluno, para uma nova forma de planejamento escolar, para a diferente e melhor utilização dos espaços e dos recursos didáticos e dos conteúdos a serem ensinados. Alguns docentes mostraram que a crítica promovida pelo curso motivou mudança em suas instituições. Uma das entrevistadas tornou-se docente do Colégio Pedro II. Algusm respodentes também relataram mudança comportamental diante dos problemas vivenciados e com relação ao tato com os colegas.

Enfim, a importância do programa, e o auxílio que ele proporcionou aos professores iniciantes, corroboram Zeichner (2010), e o relatório da OCDE (2006), o quais enfatizam a importância de programas de apoio a professores iniciantes e do auxilio para que apliquem o conhecimento adquirido durante o processo formação na complexidade do ensino em sala de aula.

\section{Contribuição das atividades do programa para a prática docente}

No sétimo eixo, "contribuição das atividades do Programa com a prática docente", inserimos todas as atividades do Programa descritas no site do PRD, de forma que os respondentes pudessem avaliar sua contribuição. De acordo com o resultado, os docentes que participaram da pesquisa consideraram que a maior parte das atividades do programa contribuiram muito com sua prática profissional, exceto pelas atividades dos setores administrativos-pedagógicos. Contudo, alguns problemas foram relatados nas respostas à questão aberta: 
Com relação à orientação tivemos bastante dificuldade devido à greve e disponibilidade da supervisora. P9

Ao final do Curso, eu e as minhas duas colegas tivemos muitas dificuldades com relação à entrega do Produto Final, a Coordenadora e a Supervisora tiveram alguns desentendimentos; esta última também teve problemas de saúde, que comprometeu um pouco a entrega do meu trabalho final. P10

Acredito que a observação do cotidiano do Colégio Pedro II foi fundamental para a minha formação. Lamento que não pude estar mais vezes devido os desgastes na escola de origem. P11 Devido à necessidade de cumprir a carga horaria exigida, me inscrevi em cursos, e palestras apenas olhando os horários compatíveis com o meu, independente do assunto abordado. P29

Nesse caso, foram citados problemas relativos à carga horária e à dificuldade na orientação do trabalho final. Além dos problemas que citamos em itens anteriores, perguntamos, durante as entrevistas, o que os docentes mudariam no curso. Foram dadas algumas sugestões de mudança, a saber: declaração de dispensa do trabalho; relação mais próxima com a escola do professor; que o curso fosse só para professores inexperientes; que houvesse mais conhecimentos teóricos; que o curso também fosse voltado aos professores mais experientes; que houvesse mais encontros relativos às áreas específicas dos professores.

Entretanto, as entrevistas com os coordenadores do curso forneceram algumas explicações sobre a necessidade da dispensa da carga horária e da não possibilidade de oferecer declaração de dispensa, do curso ser voltado ao professor iniciante de escola pública, sobre a estrutura e o início do curso, e sobre a evasão/abandono do curso pelos participantes.

Enfim, os dados descritos acima e as narrativas podem ser analisados mais profundamente para permitir o conhecimento mais acurado das dificuldades vividas pelos docentes, da dinâmica do curso e do auxílio que ele pode oferecer ao docente, especialmente àquele em início de carreira. Contudo, os dados apresentados mostram a importância das iniciativas de apoio a professores iniciantes, dos aspectos positivos que foram citados que podem ser ampliados em outros programas, bem como das críticas e aspectos negativos, citados nesta pesquisa, que precisam ser revistos entre outros aspectos.

Cabe destacar que este o programa aqui avaliado dá apoio aos professores iniciantes. Como indicado por uma das coordenadoras, ele foi estruturado como estratégia de formação continuada. Por isso, consideramos que as interpretações decorrentes do processo de pesquisa são específicas, e pertencentes ao universo aqui investigado. Assim, não pretendemos que tornem-se universais. Contudo, acreditamos que o presente estudo tem forte potencial para contribuir com o desvendamento de questões pertinentes aos programas de apoio a docentes em início de carreira - de indução profissional.

\section{CONCLUSÕES}

Em primeiro lugar ${ }^{4}$, queremos destacar a importância do Programa Residência Docente do Colégio Pedro II por ser pioneiro em ações de indução profissional no país. Acrescentamos que, de acordo com os resultados apresentados, as estratégias que o programa utilizou trouxeram muitos benefícios aos docentes que participaram dele. Não obstante, elas podem ser aperfeiçoadas com base nas críticas efetuadas pelos docentes através do questionário e das entrevistas. Algumas delas já foram identificadas pelos coordenadores, os quais também as mencionaram durante as entrevistas que realizamos com eles.

A aplicação dos questionários e as entrevistas nos permitiram afirmar que docentes buscam esse programa, acima de tudo, para adquirir conhecimento e para receber apoio para superarem as dificuldades vividas, para receberem a certificação do curso, e por ele ser gratuito. Enfatizamos as dificuldades experienciadas pelos professores antes de ingressarem no programa, e a grande importância dele para a atuação profissional dos docentes que participaram, assim como a importância dos supervisores, da troca de conhecimento, do fato de o Colégio Pedro II ser modelo em metodologias

\footnotetext{
${ }^{4}$ Queremos deixar claro que reconhecemos que as análises aqui apresentadas sobre todos os aspectos investigados poderiam ser aprofundadas, bem como apresentar mais dados e tabelas que elaboramos sobre cada eixo, mas como um artigo tem suas limitações de formato, isto só seria possível em vários artigos específicos sobre cada temática abordada.

Educação em Revista|Belo Horizonte|v.37|e32723|2021
} 
modernas e das discussões práticas efetuadas durante o curso, as quais levaram a mudanças significativas na atuação profissional dos participantes.

Entretanto, alguns respondentes também apontaram aspectos negativos do curso, que tiveram dificuldades durante o Programa por causa deles, com destaque para a não liberação do trabalho para a realização da parte prática do curso. Tal fato fez com que alguns participantes desistissem do curso. $\mathrm{O}$ fato de tratar-se de um colégio modelo, que não tem a mesma estrutura do local de trabalho dos participantes também foi apontado como um problema, assim como o fato do curso ser igual a um estágio; de, às vezes, faltar diálogo; da distância longa a ser percorrida entre o trabalho e o local do curso; do pouco conhecimento teórico oferecido pelo curso, na opinião de alguns; das dificuldades na orientação do trabalho final.

Os docentes também ofereceram sugestões para melhoria do curso, como: declaração de dispensa do trabalho; relação mais próxima com a escola do professor participante do curso; que o curso fosse só para profissionais inexperientes. Outros participantes ainda apontaram que o curso também deveria ser voltado para profissionais mais experientes; que oferecesse mais conhecimento teórico; que houvesse mais encontros relativos às áreas específicas dos professores.

Também observamos a necessidade de maior comunicação entre os envolvidos no programa, com base na citação em algumas entrevistas e em alguns questionários, ou das declarações dos supervisores do programa e orientadores regentes do CPII. Na maior parte das vezes, ninguém do programa vai à escola do docente, nem entra em contato com ela, e tal fato pode criar dificuldades para o professor adotar as práticas pedagógicas e o conhecimento adquiridos.

Pretendemos, portanto, como resultado desta pesquisa, divulgar a necessidade de expandir os programas de indução profissional para apoiar professores iniciantes nos sistemas de ensino e em todas as instituições formadoras de professores. De acordo com o que indicam os resultados do programa que investigamos, tal apoio promove a melhor qualificação dos professores e, consequentemente, a melhoria da qualidade do ensino, pois supre a já demonstrada carência de experiência por parte de professores recém formados, no ambiente escolar. Assim, esses novos profissionais contariam com a supervisão dos docentes em atividade e das instituições de ensino superior e de formação de professores.

Enfim, nossa pesquisa possibilitou confirmarmos a) a importância de dar apoio a professores iniciantes; b) a necessidade de ampliar-se as poucas experiências existentes nessa área, no Brasil; c) a necessidade de pesquisas abrangentes sobre essas experiências, no Brasil, e no mundo, de forma contextualizada, para que seja possível analisar as melhores formas de ampliar o apoio dado a professores iniciantes.

\section{REFERÊNCIAS}

ALARCÃO, Isabel; ROLDÃO, Maria do Céu. Um Passo importante no desenvolvimento profissional dos professores: o ano da indução. Form. Doc., Belo Horizonte, v. 06, p. 109-126, ago/dez. 2014.

ANDRÉ, Marli. Políticas e programas de apoio aos professores iniciantes no Brasil. Cadernos De Pesquisa, v.42 n.145, p.112-129, jan./abr. 2012. Disponível em: http://www.scielo.br/pdf/cp/v42n145/08.pdf. Acesso em: 20/11/2017.

BEACH, Richard; PEARSON, Donna. Changes in preservice teachers' perceptions of conflicts and tensions. Teaching and teacher education, Londres, vol. 14, no. 3, p. 337-351, 1998.

BOLÍVAR, António et al. La investigación biográfico-narrativa en educación. Madrid: La Muralla, 2001. 328 p.

CARDOSO, Nelson; FERREIRA, Fernando Idílio. A problemática da indução profissional no ensino: o estado da arte em Portugal. A Tutoria e Mediação em Educação: Novos Desafios à Investigação Educacional. In: XVI Colóquio AFIRSE/ AIPELF, Lisboa, 2008. 
COCHRAN-SMITH, Marilyn et al. A Longitudinal Study of Teaching Practice and Early Career Decisions: A Cautionary Tale. American Educational Research Journal, vol. 49, n. 5, p. 844-880, October 2012,

CORRÊA, Priscila Monteiro; PORTELLA, Vanessa Cristina Máximo. As pesquisas sobre professores iniciantes no Brasil: Uma revisão. Olhar de Professor, Ponta Grossa, vol. 15, n. 2, p. 223-236, 2012.

COSTA, Christine Sertã. O programa de residência docente do Colégio Pedro II: uma página recente da sua história. Mimeo. 2017.

FLORES, Maria Assunção; FERREIRA, Fernando Ilídio. The Induction and Mentoring of New Teachers in Portugal: contradictions, needs and opportunities. Research in Comparative and International Education, Volume 4, Number 1, 2009. Disponível em: http://journals.sagepub.com/doi/pdf/10.2304/rcie.2009.4.1.63. Acesso em 05/06/2017.

HUBERMAN, Michael. O ciclo de vida profissional dos professores. In: NÓvOA, António (Org.). Vidas de professores. 2. ed. Porto: Porto, 2000. p. 31-61.

LIEBLICH, Amia; TUVAL-MASHIACH, Rivka; ZILBER, Tamar. Narrative research: reading, analysis and interpretation. Vol. 47: Applied Social research methods. Thousand Oaks: Sage, 1998. 200 p.

LIMA, Emília. A construção do início da docência: reflexões a partir de pesquisas brasileiras. Revista do Centro de Educaşão, Universidade Federal de Santa Maria, v. 29, n. 2, 2004.

MARCELO, Carlos. Estudio sobre estratégias de inserción profesional en Europa. Revista Iberoamericana de Educación, 19, enero-abril. 1999. Disponível em<http://www.rieoei.org/oeivirt/rie19a03.htm>. Acesso em 05/06/2017.

MARTINS, António Maria. Escola e mercado de trabalho em Portugal: imperativos de mudança e limites de realização. Tese (Doutorado em Ciências da Educação). Aveiro: Universidade de Aveiro, 1996.

NÓVOA, António. Firmar a posição como professor, afirmar a profissão docente. Cad. Pesqui., vol. 47, n. 166, p. 1106-1133, 2017.

OCDE. Professores são importantes: atraindo, desenvolvendo e retendo professores eficazes. São Paulo: Editora Moderna, 2006. 252 p.

PAPI, Silmara de Oliveira Gomes; MARTINS, Pura Lúcia Oliver. O Desenvolvimento Profissional de professores iniciantes e as pesquisas iniciantes. In: VIII EDUCERE e o III CIAVE. PUC-PR, 2008.

PONTE, João Pedro da, et al. Histórias de investigações matemáticas. Lisboa: Instituto de Inovação Educacional, 1998. 130 p.

RABELO, Amanda Oliveira; MONTEIRO, Ana Maria. Apresentação da sessão temática: Indução profissional: desafios e experiências entre formação e profissão docente. Currículo sem fronteiras, v. 19, p. 5-22, 2019

RABELO, Amanda Oliveira. Análise Comparada Da Indução Profissional Como Apoio Ao Docente Iniciante. Curriculo sem fronteiras, v. 19, p. 81-96, 2019.

SAMPIERI, Roberto Hernández; COLLADO, Carlos Hernández; LUCIO, Pilar Baptista. Metodologia de pesquisa. 3. ed. São Paulo: McGraw Hill, 2006. 624 p. 
SILVA, Maria Celeste. O Primeiro Ano de Docência: O Choque com a Realidade. In: ESTRELA, Maria T.(org.) Viver e construir a profissão docente. Porto: Porto Editora, Colecạao Ciencias da Educacạa, n. 26, p.51$80,1997$.

ZEICHNER, Ken M. Rethinking the Connections Between Campus Courses and Field Experiences in College and University-based Teacher Education. Educação, Santa Maria, v.35 n.3, p479-504, set/dez 2010.

Submetido: $14 / 08 / 2018$

Aprovado: 06/07/2021 